\section{Discurso del Presidente de la Sociedad Médica de Santiago en responso por Dr. Victorino Farga C.}

Santiago, 17 de julio de 2019

En nombre de la Sociedad Médica de Santiago (Sociedad Chilena de Medicina Interna), cumplo con el penoso deber de dar un último adiós, a uno de nuestros más queridos e ilustres Socios, el Dr. Victorino Farga Cuesta.

Durante los más de 50 años que el Dr. Farga perteneció a nuestra Sociedad, destacó siempre por su calidad humana, médica y científica, enseñando y compartiendo sus excelsos conocimientos de neumotisiología con múltiples generaciones de médicos. En todo este período, él fue para muchos de nosotros ejemplo y modelo de como el conocimiento profundo de un tema en medicina, al cultivarlo en equipo, con innovación y perseverancia, pueden fructificar en beneficio de los pacientes más necesitados, no solo del nuestro, sino que también de muchos otros países en el mundo y elevando con este trabajo, el prestigio de la medicina chilena. El Dr. Farga, así nos demostró, con su labor y temple que es posible superar los múltiples desafíos que en la práctica de la medicina y por cierto, también en la vida, podemos encontrar.

Por ello, en el año 2013, nuestra Sociedad lo distinguió con el título de "Maestro de la Medicina Interna", el más alto honor que confiere la Sociedad Médica de Santiago y que reconoció de esta forma, el principal legado profesional del Dr. Farga, su infatigable lucha contra la tuberculosis. Al despedirlo hoy, quizá más que todas estas palabras, importa resaltar esto, el enorme y benéfico impacto que la obra del Dr. Victorino Farga tuvo en miles de pacientes con tuberculosis, los cuales, gracias a él salvaron su vida y pudieron curarse de esta penosa enfermedad.

Finalizo este adiós, expresando nuestro pésame a su esposa, Dra. Eliana Ceruti, a toda su familia y amigos, con la convicción que el dolor de su partida, será mitigado por el recuerdo imborrable, de una larga, plena y fructífera vida de servicio.

Descanse en paz Dr. Victorino Farga.

Dr. Gilberto González V. ${ }^{1}$ ${ }^{1}$ Presidente Sociedad Médica de Santiago 